\title{
Direitos Fundamentais, Relações Privadas e Autonomia dos Associados
}

\author{
Lenio Luiz Streck ${ }^{1}$ \\ Professor Titular da UNISINOS-RS \\ Mário De Conto² \\ Mestre e Doutorando em Direito pela UNISINOS
}

Sumario: I. Introdução. II. O Acórdão e os precedentes jurisprudenciais do Superior Tribunal de Justiça. III. Os Pressupostos da Decisão. 3.1. Do Direito Econômico e da Livre Concorrência. 3.2. Cláusula de Exclusividade: impossibilidade no aspecto individual e difuso. IV. Considerações Finais.

Resumo: No presente trabalho, pretende-se investigar qual o grau de autonomia que o associado de uma Cooperativa dispõe para realizar operações com outras sociedades cooperativas que atuam no mercado como concorrentes. Este estudo desenvolve-se por meio dos aportes do Direito Concorrencial e do Direito Cooperativo, e também mediante uma análise crítica da jurisprudência do Superior Tribunal de Justiça.

Palavras chave: associado, direitos fundamentais, direito concorrencial.

Abstract: This paper intends to investigate the degree of autonomy that the associate of a Co-operative has to make operations with other co-operative societies that actuate in the market as competitors. This study is based on the contributions of Competition Law and Cooperative Law, and examines critically the jurisprudence from the Superior Court of Justice about the subject.

Key-words: associate, competition Law, fundamental rights.

1 Doutor em Direito do Estado (UFSC) e Pós-Doutor em Direito (Universidade de Lisboa). Professor Titular da UNISINOS-RS; Pesquisador da Universidad de Deusto-ES; Professor Visitante da Universidad Javeriana de Bogotá.

2 Mestre e Doutorando em Direito pela UNISINOS. Gerente Jurídico do Sindicato e Organização das Cooperativas do Estado do Rio Grande do Sul. Coordenador de Ensino, Pesquisa e Extensão da Faculdade de Tecnologia do Cooperativismo - ESCOOP. 


\section{Introdução}

A problemática que se pretende apresentar, no presente estudo, concerne à possibilidade de estipulação, por parte de associados de uma Cooperativa, de cláusula estatutária que não permita que o associado opere com outra empresa que atua no mercado como concorrente da Cooperativa.

Dito de outro modo, trata-se de verificar, segundo o ordenamento jurídico brasileiro, se os associados dispõem de autonomia para, através do estabelecimento de disposições estatutárias, limitar a liberdade do associado na realização de operações com outras empresas que, na ordem prática, disputam mercado com a sociedade cooperativa da qual o associado é membro.

No caso que será analisado no presente estudo - o caso de uma Cooperativa de Trabalho Médico qualificada como uma Operadora de Planos de Saúde Privados - acresce-se ao tema a discussão de temas de Direito Concorrencial. Nesse sentido, verificar-se-á a jurisprudência do Superior Tribunal de Justiça acerca da matéria, os pressupostos da decisão e sua critica à luz do Direito Cooperativo.

Nesses termos, na medida em que o objetivo do presente estudo é analisar a questão da autonomia dos associados, o tema requer a análise da disciplina jurídica das sociedades cooperativas, bem como insere-se no contexto da eficácia dos Direitos Fundamentais nas relações entre particulares.

\section{O Acórdão e os precedentes jurisprudenciais do Superior Tribunal de Justiça}

O Acórdão ora analisado foi prolatado nos autos do Recurso Especial n. 11.172.603-RS, em que foi recorrente o Conselho Administrativo de Defesa Econômica - CADE e recorrida a UNIMED Santa Maria - Sociedade Cooperativa de Serviços Médicos Ltda., cuja ementa se transcreve:

DIREITO ECONÔMICO - LIVRE CONCORRÊNCIA - INEXISTÊNCIA DE VIOLAÇÃO DO Art. 535 DO CPC - UNIMED - COOPERATIVA DE SAÚDE - SUBMISSÃO IRRESTRITA ÀS NORMAS JURÍDICAS QUE REGULAM A ATIVIDADE ECONÔMICA - CLÁUSULA DE EXCLUSIVIDADE PARA MÉDICOS COOPERADOS - IMPOSSIBILIDADE TANTO SOB O ASPECTO INDIVIDUAL QUANTO SOB O ASPECTO DIFUSO - INAPLICABILIDADE AO PROFISSIONAL LIBERAL DO § 40 DO AR- 
TIGO 29 DA LEI N. 5.764/71, QUE EXIGE EXCLUSIVIDADE - CAUSA DE PEDIR REMOTA VINCULADA A LIMITAÇÕES À CONCORRÊNCIA - VIOLAÇÃO, PELO TRIBUNAL DE ORIGEM, DO Art. 20, INCISOS I, II E IV; DO Art. 21, INCISOS IV E V, AMBOS DA LEI N. 8.884/94, E DO Art. 18, INCISO III, DA LEI N. 9.656/98 - INFRAÇÕES AO PRINCÍPIO DA LIVRE CONCORRÊNCIA PELO AGENTE ECONÔMICO CONFIGURADAS.

1. (...)

2. A Constituição Federal de 1988, ao tratar do regime diferenciado das cooperativas não as excepcionou da observância do princípio da livre concorrência estabelecido pelo inciso IV do art. 170.

3. A causa de pedir remota nas lides relativas a cláusula de exclusividade travadas entre o cooperado e a cooperativa é diversa da causa de pedir remota nas lides relativas a direito de concorrência. No primeiro caso, percebe-se a proteção de suposto direito ou interesse individual; no segundo, a guarda de direito ou interesse difuso. Portanto, inaplicáveis os precedentes desta Corte pautados em suposto direito ou interesse individual.

4. Ao médico cooperado que exerce seu labor como profissional liberal, não se aplica a exigência de exclusividade do § 40 do art. 29 da Lei n. 5.764/71, salvo quando se tratar de agente de comércio ou empresário.

5. A cláusula de exclusividade em tela é vedada pelo inciso III do art. 18 da Lei n. 9.656/98, mas, ainda que fosse permitida individualmente a sua utilização para evitar a livre concorrência, através da cooptação de parte significativa da mão-de-obra, encontraria óbice nas normas jurídicas do art. 20, I, II e IV, e do art. 21, IV e V, ambos da Lei n. 8.884/94. Portanto, violados pelo acórdão de origem todos aqueles preceitos.

6. Ainda que a cláusula de exclusividade não fosse vedada, a solução minimalista de reputar lícita para todo o sistema de cláusula contratual, somente por seus efeitos individuais serem válidos, viola a evolução conquistada com a criação da Ação Civil Pública, com a promulgação da Constituição Cidadã de 1988, com o fortalecimento do Ministério Público, com a criação do Código de Defesa do Consumidor, com a revogação do Código Civil individualista de 1916, com a elaboração de um futuro Código de Processos Coletivos e com diversos outros estatutos que celebram o interesse público primário.

Recurso especial provido.»

A decisão recorrida (do Tribunal Regional Federal da Quarta Região, instância de apelação da justiça federal brasileira) e que fora objeto de reforma pelo Superior Tribunal de Justiça - deu validade à cláusula de exclusividade, como se verifica da ementa: 
ADMINISTRATIVO. MÉDICOS COOPERADOS. UNIMED. CLÁUSULA DE EXCLUSIVIDADE. VALIDADE.

É válida a cláusula do estatuto social que impõe aos médicos cooperados o dever de exclusividade, já que de acordo com a natureza do cooperativismo, na medida em que o cooperado é sócio e não vai concorrer com ele mesmo. Entendimento do STJ.» (fls. 735e/740e).

Com efeito, a decisão do Tribunal Regional da Quarta Região observou os precedentes existentes à época do Superior Tribunal de Justiça, no sentido de dar validade às disposições estatutárias estabelecidas pelos associados em Assembleia Geral:

COMERCIAL - COOPERATIVA (UNIMED) - ATO DA ASSEMBLEIA -
ESTATUTOS.
I - No direito cooperativo, assentou a doutrina que os estatutos contém as normas fundamentais sobre a organização, a atividade dos órgãos e os direitos e deveres dos associados rente a associação. São disposições que valem para todos os partícipes (cooperativas) por isso que de natureza geral e abstrata, tal como a constituição reguladora da vida do estado rege o comportamento das sociedades personificadas. Tais normas não assumem uma característica contratual, mas regulamentar ou institucional.

II - O associado que adere a Cooperativa Médica sujeita-se a seu estatuto. Não está obrigado a não atuar livremente no atendimento a pacientes que o procurem. Todavia não pode vincular-se a outra entidade congenere, provocando concorrência à cooperativa e desvirtuando a finalidade com que instituída.

III - Recurso conhecido e provido.

Recurso Especial n. 126.391-SP, Relator: Min. Waldemar Zveiter, 3a turma, 3 de agoso de 1999.

\section{Os Pressupostos da Decisão}

Inicialmente verifica-se que a jurisprudência do Superior Tribunal de Justiça, a partir do Recurso Especial n. 11.172.603-RS, sofreu radical transformação, migrando do entendimento até então adotado pelo Tribunal (o de conferir validade à cláusula estatutária de exclusividade) para negar sua validade considerando-se dispositivos legais atinentes à Livre Concorrência.

Com efeito, os argumentos apresentados pelo recorrente - o Conselho Administrativo de Defesa Econômica - CADE - foram no sentido de que a cláusula de exclusividade impede a entrada e a per- 
manência de concorrentes no mercado, visto que os outros agentes econômicos não conseguem manter um número aceitável de médicos conveniados. A partir de tal tese do recorrente, analisam-se os pressupostos da decisão com vistas a sua análise a partir do Direito Cooperativo.

\section{III.1. Do Direito Econômico e da Livre Concorrência}

A decisão centra-se no entendimento de que a cláusula de exclusividade fere o Princípio Constitucional da Livre Concorrência insculpido no art. 170, inciso IV da Constituição Federal e que as Cooperativas a despeito das disposições constitucionais no sentido de que o Estado deve apoiar e estimular o Cooperativismo - estão, igualmente, subordinadas a sua observância.

Chama a atenção que, segundo a decisão, a Cláusula de Exclusividade é vedada pelos arts. 18 da Lei 9.656/98 e pelos arts. 20, I, II e IV, e 21, IV e V, ambos da Lei n. 8.884/94, o que não nos parece compatível com a disciplina jurídica das sociedades cooperativas, consideradas enquanto sociedades democráticas, em que os médicos são seus associados (donos e usuários), a quem incumbem as decisões mais relevantes da sociedade, tomadas em Assembleia Geral.

Veja-se, nesse sentido, o que dispõe o art. 18 da Lei 9.656/98, que dispõe sobre os «planos e seguros privados de assistência à saúde», o comando legal pretensamente infringido pelas Cooperativas Medicas que atuam como Operadoras de Planos de Saúde Privados. Segundo o dispositivo:

Art. 18. A aceitação, por parte de qualquer prestador de serviço ou profissional de saúde, da condição de contratado, credenciado ou cooperado de uma operadora de produtos de que tratam o inciso I e o § 10 do art. 10 desta Lei, implicará as seguintes obrigações e direitos: (Redação dada pela Medida Provisória n. ${ }^{\circ} 2.177-44$, de 2001)

$$
\text { (...) }
$$

III - a manutenção de relacionamento de contratação, credenciamento ou referenciamento com número ilimitado de operadoras, sendo expressamente vedado às operadoras, independente de sua natureza jurídica constitutiva, impor contratos de exclusividade ou de restrição à atividade profissional ${ }^{3}$. (Redação dada pela Medida Provisória n. ${ }^{\circ}$ 2.177-44, de 2001).

\footnotetext{
3 Sem grifos no original.
} 
Segundo preconiza o dispositivo supracitado, as Operadoras não podem impor contratos de exclusividade aos profissionais (no caso, os médicos associados). Percebe-se, nesse ínterim, que a Cooperativa, considerando-se sua característica instrumental, não possui, enquanto pessoa jurídica, a competência de impor tais cláusulas aos seus associados, notadamente no que tange a cláusula de exclusividade, que se trata de uma disposição estatutária, sempre aprovada em Assembleia Geral Extraordinária, em que os médicos associados é que tomam tal decisão.

Com efeito, de acordo com a definição legal constante do art. $3^{\circ}$ da Lei 5764/71, "celebram contrato de sociedade cooperativa as pessoas que reciprocamente se obrigam a contribuir com bens ou serviços para o exercício de uma atividade econômica, de proveito comum, sem objetivo de lucro». Ainda, segundo o art. $4^{\circ}$ da Lei 5764/71, por sua vez, dispõe que "as cooperativas são sociedades de pessoas, com forma e natureza jurídica próprias, de natureza civil, não sujeitas a falência, constituídas para prestar serviços aos associados (...)».

Da análise dos dois dispositivos, pode-se verificar que os associados de um Sociedade Cooperativa objetivam desenvolver uma atividade econômica em comum ${ }^{4}$. Nesses termos, a Sociedade Cooperativa é um instrumento dos associados para a prestação de serviços para estes. É essa, inclusive, a determinação legal do art. 7 da Lei 5764/71, que dispõe que as «cooperativas singulares se caracterizam pela prestação direta de serviços aos associados».

Nesses termos, parece-nos evidente o equívoco em considerar a relação estabelecida entre a Cooperativa e seus associados como análoga a estabelecida entre uma Operadora (não cooperativa) e seus contratadosconveniados. Se na relação estabelecida entre estes últimos e uma Operadora não Cooperativa se estabelece uma relação de subordinação pura e simples, em que o medico contratado-conveniado não possui qualquer

4 Para Walmor Franke, a expressão «celebram contrato de sociedade cooperativa«, na dicção do art. 3o da Lei 5764/71 não expressa relação com interesses antagônicos. Nas suas palavras: "Sustenta-se que os fundadores de uma corporação não se encontram, no ato de sua constituição, frente a frente, em posição antagônica, como portadores de interesses diversos e, muitas vezes, opostos, como acontece, por exemplo, nos contratos de compra e venda, permuta, locação etc.; nem se tornam, por efeito do ato constitutivo, credores recíprocos de prestações cujo cumprimento redunde, para os fundadores, na satisfação de uma vantagem individual, diferenciada e distinta. Visam, isto sim, conjuntamente, por meio de promessas prestacionais realizadas em função de um mesmo fim, à criação de um ente jurídico - a sociedade personificada. Como novo sujeito de direitos e obrigações, passa esta a atuar, nesta qualidade, no mundo jurídico, não só em relação a terceiros, estranhos ao ato social constitutivo, como perante os próprios membros, fundadores e futuros aderentes». FRANKE. Walmor. Direito das Sociedades Cooperativas. São Paulo: Saraiva, 1978, p. 46. 
poder de decisão, cabendo-Ihe unicamente acatar as imposições da Operadora, no caso da relação entre a Cooperativa e seu medico associado, este é o dono do negócio, decidindo democraticamente acerca das regras. Nesse caso, há convergência de interesses da Cooperativa e do Medico associado, não havendo relação de conflito de interesses.

Aliás, oportuno referir que a doutrina tem apontado que tal característica das sociedades cooperativas - a convergência de interesses entre Cooperativa e seus associados- é responsável pela incompreensão de tais sociedades pelo Direito Contemporâneo, notadamente estruturado para regular relações de conflito. Nas palavras de Ovídio Baptista da SILvA:

As dificuldades na compreensão do que seja uma cooperativa reside essencialmente nisso. O Direito, na sua dimensão subjetiva, é compreendido, no direito moderno, como uma relação de conflito de interesses, não como uma relação de "conflito de interesses», não como uma relação «cooperativa», nunca como uma conduta solidária, entre os sujeitos de uma determinada relação jurídica 5 .

Nesses termos, a decisão comentada, ao aplicar a relação estabelecida entre a Cooperativa e seus Médicos um normativo aplicável a operadoras que impõem a cláusula de exclusividade a seus contratados, deixa de observar as peculiaridades das sociedades cooperativas. No caso de tais sociedades, o interesse do associado é convergente, na medida em que o fim buscado pelo associado é semelhante ao fim da Cooperativa, considerando-se o princípio da identidade ${ }^{6}$ que rege tais relações. Nas palavras de FrANKE:

5 SILVA, Ovídio Araújo Baptista da. O seguro e as sociedades cooperativas: relações jurídicas comunitárias. Porto Alegre: Livraria do Advogado Editora, 2008, p. 19.

6 Franke apresenta exemplos de consecução do princípio da identidade. "As cooperativas de habitação se ocupam com a construção ou compra de casas de moradia, para alugá-las ou transmiti-las aos cooperados. Ao contrário do que acontece na forma clássica dos contratos obrigacionais (do ut des, facio ut facias etc.), não existe antagonismo de interesses nos contratos para aquisição de casa própria realizados entre cooperativa e associado. Como acentua a doutrina, «ainda que o estatuto-tipo se refira a 'alienação de casa para moradia própria' e a 'preço de compra', não se trata de compra e venda na acepção do Código Civil, mas do cumprimento de uma relação jurídica de natureza cooperativa, em que não pode ingressar quem não seja associado «. Também a entrega da casa para uso do associado não configura, propriamente, um contrato de locação, mas uma relação jurídica de uso, de natureza especial, que radica, institucionalmente, nas normas estatutárias da sociedade. A relação jurídica de uso se extingue quando o usuário deixa de ser sócio da cooperativa. Em todos esses casos, o fim da cooperativa se identifica com o de sua clientela, funcionando a sociedade como instrumento de satisfação das necessidades domésticas e empresariais dos cooperados.FRANKE. Walmor. Direito das Sociedades Cooperativas. São Paulo: Saraiva, 1978, p. 16-17. 
Os negócios jurídicos que a cooperativa realiza internamente com seus membros, para incrementar-lhes a situação econômica, regemse pelo principio de identidade. O interesse do cooperado e o da cooperativa, nessas operações, obedece à mesma causa (final): a cooperativa visa a servir o associado, para melhorar sua posição econômica, e o associado serve-se da cooperativa para o mesmo fim $^{7}$ ».

Nesse sentido, as regras são estabelecidas pelos próprios associados, no que Ovídio Baptista da SiLva denomina de relação de índole "associativa ou comunitária», circunstância presente na principiologia constitucional:

Daí dizer-se que, ao contrario das demais formações jurídicas de índole econômica, nas cooperativas as relações que se estabelecem entre cada associado e a entidade não serão relações jurídicas bilaterais, que interessem apenas aos respectivos participantes. Serão sempre relações de índole associativa ou comunitária ${ }^{8}$.

A partir de tais premissas, verifica-se a inaplicabilidade do dispositivo às Sociedades Cooperativas. Não pelo fato de que o Princípio da Livre Concorrência não as alcance - já que se trata de Princípio Constitucional atinente a toda a ordem econômica- mas pelo motivo de que, segundo a sua própria disciplina jurídica, as decisões não são impostas aos associados, mas deliberadas pelos mesmos, considerados enquanto donos e usuários do empreendimento coletivo.

III.2. Cláusula de Exclusividade: impossibilidade no aspecto individual e difuso

O segundo macro argumento da decisão concerne ao entendimento exposto na Ementa do Acórdão de que

«a causa de pedir remota nas lides relativas a cláusula de exclusividade travadas entre o cooperado e a cooperativa é diversa da causa de pedir remota nas lides relativas a direito de concorrência. No primeiro caso, percebe-se a proteção de suposto direito ou interesse individual; no segundo, a guarda de direito ou interesse difuso. Portanto, inaplicáveis os precedentes desta Corte pautados em suposto direito ou interesse individual».

7 FRANKE. Op. cit., p. 23.

8 SILVA, Ovídio Araújo Baptista da. O seguro e as sociedades cooperativas: relações jurídicas comunitárias. Porto Alegre: Livraria do Advogado, 2008, p. 143. 
Na fundamentação, o Ministro Relator apresenta argumentos de que a cláusula de exclusividade viola direitos coletivos lato sensu, considerando tratar-se de lide que versa acerca do Direito da Concorrência. Nas suas palavras:

A tábua dos direitos coletivos lato sensu pode ilustrar situações peculiares em relação a uma mesma cláusula contratual, visto que o comando pode ser individualmente válido, mas coletivamente (coletivo e difuso) inválido.

(...)

Ora, ainda que a cláusula contratual de exclusividade não encontrasse óbice no inciso III do art. 18 da Lei n. 9.656/98, questionar-seia a sua validade quando a multiplicidade dos seus efeitos pudesse violar direitos coletivos lato sensu.

Hipoteticamente, exigir contratualmente - o estatuto social não deixa de ter natureza jurídica de contrato - exclusividade de profissionais da construção civil sem que isto tornasse inviável a atuação de outros agentes econômicos não violaria o ordenamento pátrio.

O mesmo poderá ser dito quando tal cláusula impedir a atuação de outros agentes econômicos?

A solução minimalista de reputar lícita para todo o sistema de cláusula contratual somente por seus efeitos individuais serem válidos viola a evolução conquistada com criação da Ação Civil Pública, com a promulgação da Constituição Cidadã de 1988, com o fortalecimento do Ministério Público, com a criação do Código de Defesa do Consumidor, com a revogação do Código Civil individualista de 1916, com a elaboração de um futuro Código de Processos Coletivos e com diversos outros estatutos que celebram o interesse público primário?.

Dito de outro modo, o argumento se encontra no bojo do que se denomina de "publicização do Direito Privado», notadamente da noção de restrição da Autonomia Privada em prol da consecução de um «interesse público primário». Todavia, verifica-se que tal «interesse público primário» - o de aumentar a concorrência no setor- é alcançado através da restrição da autonomia dos associados da Sociedade Cooperativa a quem, conforme referido, não são impostos contratos de exclusividade, mas decidem, democraticamente, as regras do empreendimento do qual são associados. Assim, a tese da publicização mostra-se paradoxal, mormente se examinada à luz daquilo que sustenta o próprio cooperativismo: a liberdade e a autonomia dos associados.

9 Sem grifos no original. 
Veja-se, a doutrina no Brasil tem se atentado para a aplicabilidade dos Direitos Fundamentais às relações privadas notadamente sob o enfoque da proteção que as entidades devem conferir aos Direitos Fundamentais de seus associados. Dito de outro modo, não se conceberia que as relações privadas estivessem imunes aos Direitos Fundamentais constitucionalmente consagrados, motivo pelo qual a disciplina jurídica das associações privadas -e no caso desse trabalho, das sociedades cooperativas - vinculam-se a observância de tais direitos, como bem anota André Rufino do Vale:

«A idéia de um ordenamento jurídico invadido pela Constituição faz transparecer a noção de associações privadas responsáveis pelos direitos fundamentais de seus associados. Constitucionalizar a ordem juridica privada significa também submeter o ordenamento jurídico interno dos organismos privados aos princípios constitucionais. Não se trata de restringir ou anular a autonomia privada das associações, mas de reafirmar que a liberdade de associação, assegurada pelo art. 50., incisos XVII a XX da Constituição, não pode e não deve ser absoluta, mas sim precisa estar em harmonia com todo o sistema de direitos fundamentais ${ }^{10}$ ».

A problemática apresentada nessa análise, todavia, perscruta outro prisma: o fato de que a autonomia dos associados feriria pretenso Direito Coletivo - que não o Direito dos Associados. Dito de outra forma: a decisão sob comento optou por restringir um Direito Fundamental a autonomia privada dos associados da Cooperativa - em detrimento de «direitos coletivos lato sensu» ou de um «interesse público primário», que seria garantir o Direito de Concorrência.

Ora, a Ordem Econômica, que deve observar a Livre Concorrência, também deve ser, como preconiza o art. 170 da Constituição, «fundada na valorização do trabalho humano e na livre iniciativa», que, a priori, não justifica a restrição da Autonomia Privada dos Médicos associados de Cooperativas. Aqui, a necessária aplicação do princípio da concordância prática, harmonizando os diversos princípios e dispositivos constitucionais. Não fosse assim, poder-se-ia fazer interpretação que anularia a própria cidadania «interna» ínsita às cooperativas. Afinal, o coletivo sempre estaria predominando sobre o individual. É evidente que isso seria simplificar a discussão.

Tal interpretação é reforçada analisando-se o texto da própria Constituição da República, em seu art. 174, § $2^{\circ}$, determina que:

10 VALE, André Rufino do. Drittwirkung de Direitos Fundamentais e Associações Privadas, in Direito Público, vol. 9/64-65, julho/setembro de 2005, IDP/Síntese. 
Art. 174. Como agente normativo e regulador da atividade econômica, o Estado exercerá, na forma da lei, as funções de fiscalização, incentivo e planejamento, sendo este determinante para o setor público e indicativo para o setor privado.

(...)

$\S 2^{\circ}$ - A lei apoiará e estimulará o cooperativismo e outras formas de associativismo ${ }^{11}$.

Nesse sentido, a atividade regulatória do Estado na economia, no contexto do Estado Democrático de Direito, deve ser no sentido de apoiar e estimular o Cooperativismo. E qual seria o sentido desse mandamento constitucional? Parece evidente a resposta. Justamente que o Cooperativismo serve à consecução de objetivos do Estado Democrático de Direito e que visa a proteção, sim, de Direitos Coletivos. A proteção que a Constituição Federal assegurou ao Cooperativismo se coaduna com a consecução dos objetivos do Estado Democrático de Direito, ao estimular um modelo econômico que, através da gestão democrática pelos associados, garante a distribuição justa das riquezas, através de critérios que valorizam o trabalho dos associados em detrimento do capital.

Deve-se atentar, que o Estado Democrático de Direito propõe-se em uma síntese aprimorada dos modelos constitucionais anteriores, ou seja, do modelo do Estado Liberal e do Estado Social. Se, por um lado, no paradigma do Estado Liberal foram reconhecidas as liberdades denominadas negativas (Direitos Fundamentais de primeira dimensão), no paradigma do Estado Social foi conferido ao Estado um papel decididamente intervencionista, através das liberdades positivas (Direitos Fundamentais de segunda dimensão) que exigem, para sua consecução, um agir por parte do Estado.

Dessa forma, considerado o Estado Democrático de Direito como esta síntese de modelos, como um Estado que visa proteger tanto o interesse individual quanto o coletivo, configuram-se tais Direitos como Direitos de Defesa e como Direitos à Prestações que necessitam, ambos, de proteção do Estado.

Tais Direitos de Defesa e Direitos a Prestações (que importam, via de regra, em abstenções e ações, por parte do Estado), remetem à análise da Dupla Face do Princípio da Proporcionalidade ${ }^{12}$, pela qual o Estado,

11 Sem grifos no original.

12 STRECK, Lenio Luiz. A dupla face do princípio da proporcionalidade: da proibição de excesso (übermassverbot) à proibição de proteção deficiente (untermassverbot) ou de como não há blindagem contra normas penais inconstitucionais. In: Revista da Associação dos Juízes do Estado do Rio Grande do Sul, Ano XXXII, Março 2005, 97. 
na sua atuação, está proibido de proteger deficientemente mas, igualmente, está proibido de agir com excessos.

Dessa forma, a resposta ao argumento apresentado na decisão sob análise merece duas considerações: a primeira é a de que a autonomia privada dos associados, no sentido de poder democraticamente definir as regras do empreendimento coletivo do qual são donos e usuários deve ser respeitada, sob pena do Estado estar agindo com excesso, violando, portanto, Direito Fundamental dos associados.

A segunda consideração é a de que a Livre Concorrência - não obstante ser princípio constitucional atinente à Ordem Econômica não pode ser interpretada isoladamente, deixando de considerar outros princípios da Ordem Econômica, como o de Apoio e Estímulo ao Cooperativismo e outras formas de Associativismo. Desconsiderar as peculiaridades das sociedades cooperativas, aplicando-lhe normas que não se coaduam com sua natureza jurídica e com isso deixar de concederIhe o estímulo e apoio preconizados pela Constituição Federal importa em uma Proteção Deficiente pelo Estado.

\section{Considerações Finais}

A partir do Recurso Especial n. 11.172.603-RS, o Superior Tribunal de Justiça passou a negar validade à Cláusula de Exclusividade considerando-a dispositivos legais atinentes à Livre Concorrência.

Os argumentos da decisão (notadamente do ferimento ao Princípio Constitucional da Livre Concorrência insculpido no art. 170, inciso IV da Constituição Federal) deixam de observar as peculiaridades das sociedades cooperativas, uma vez que, como sociedades democráticas (comunitárias, na acepção do Prof. Ovídio Baptista da SILVA), são instrumentos a favor de seus associados. Dito de outro modo, a Cooperativa, considerando-se sua característica instrumental, não possui, enquanto pessoa jurídica, a competência de impor tais cláusulas aos seus associados, notadamente no que tange a cláusula de exclusividade, que se trata de uma disposição estatutária, sempre aprovada em Assembleia Geral Extraordinária, em que os médicos associados é que tomam tal decisão.

Como constatou com maestria Baptista da SILVA, a doutrina e jurisprudência pátrias tem dificuldades de compreender a sociedade cooperativa enquanto extensão do seu associado, onde as relações jurídicas são comunitária e não bilaterais, onde os interesses são convergentes e não conflitantes. Tal dificuldade de compreensão reside, justamente, nas características do Direito e de suas raízes liberais-in- 
dividualistas, nascido para regular relações de conflito e não relações comunitárias.

Nesses termos, as disposições legais, concernentes ao Direito Concorrencial, de que a operadora de planos de saúde não podem impor aos médicos contratos de exclusividade são inaplicáveis às sociedades cooperativas, não por estarem imunes a tais dispositivos, mas pelo simples motivo de que as decisões, em uma sociedade democrática, não são impostas aos associados, mas deliberadas pelos mesmos, considerados enquanto donos e usuários do empreendimento coletivo. Caso contrário, para quê «cooperativa»?

Por fim, a restrição da autonomia privada dos associados encontra óbice no próprio contexto do Estado Democrático de Direito, entendido como síntese do modelo de Estado Liberal e Estado Social e visa, portanto, à proteção, tanto de Direitos Individuais, quanto de Direitos Coletivos. Os Direitos Fundamentais, no paradigma do Estado Democrático de Direito, considerados enquanto Direitos de Defesa e Direitos à Prestações, trazem ao Estado a Proibição do Excesso e a Proibição da Proteção Deficiente, como corolário da dupla face do Princípio da Proporcionalidade. Em síntese, se por um lado, a autonomia privada dos associados merece proteção do Estado, sob pena de o mesmo estar agindo com excesso, por outro lado, a interpretação constitucional acerca da Ordem Econômica deve considerar, além da Livre Concorrência, o Apoio e Estímulo ao Cooperativismo e outras formas de Associativismo preconizado pela Constituição Federal, sob pena de o Estado incorrer na Proteção Deficiente ao Sistema Cooperativista. 